\title{
Fatal consequences of freshwater pearl diving
}

Nguyen Hoan Phu MD ${ }^{1}$, Nguyen Thi Hoang Mai MD ${ }^{1}$, Ho Dang Trung Nghia MD Tran Thi Hong Chau MD ${ }^{1}$, Pham Phu Loc MD ${ }^{1}$, Le Hong Thai MD¹, Tran My Phuong $M D^{1}$, Cao Quang Thai $M D^{1}$, Dinh Nguyen Huy Man $M D^{1}$, Nguyen Van Vinh Chau MD ${ }^{1}$, Tran Vu Thieu Nga MSc ${ }^{2}$, James Campbell MIBMS ${ }^{2,3}$, Stephen Baker PhD ${ }^{2,3}$, James Whitehorn MRCP ${ }^{2,4 *}$

1. Hospital for Tropical Diseases, 764 Vo Van Kiet, District 5, Ho Chi Minh City, Vietnam

2. Oxford University Clinical Research Unit, Hospital for Tropical Diseases, 764 Vo Van Kiet, District 5, Ho Chi Minh City, Vietnam

3. Centre for Tropical Diseases, University for Oxford, Oxford, United Kingdom

4. Department of Clinical Research, London School of Hygiene and Tropical Medicine, London, WC1E 7HT, United Kingdom

* Correspondence to James Whitehorn, Oxford University Clinical Research Unit, Hospital for Tropical Diseases, 764 Vo Van Kiet, Ward 1, District 5, Ho Chi Minh City, Viet Nam. Email: james.whitehorn@Ishtm.ac.uk 
In July 2012, a 25-year-old man was admitted to our hospital with headache, fever and reduced level of consciousness. He had an unremarkable medical history and took no regular medications. He worked as a peanut vendor and prior to becoming unwell had visited relatives in the countryside. During this time he attended a wedding and, of note, went diving for pearls in a freshwater lake. One week after returning to the city he developed a headache and a fever, for which he took paracetamol. The next day his headache had worsened in severity and he attended his local hospital, where it was noted that he was confused. At this hospital he was given a dose of ceftriaxone to cover bacterial meningitis and was transferred to our hospital.

On initial assessment, he had a temperature of $39^{\circ} \mathrm{C}$. His Glasgow coma scale was $10(M=5, V=2, E=3)$. His neck was stiff. He had no rash and was haemodynamically stable. Initial blood tests revealed an elevated white cell count at $13.34 \times 10^{9} / \mathrm{L}$ with $89 \%$ neutrophils. A lumbar puncture was performed which showed an opening pressure of $38 \mathrm{~cm} \mathrm{H}_{2} \mathrm{O}$. The cerebrospinal fluid (CSF) contained $3260 \times 10^{3} / \mathrm{mL}$ white cells with $88 \%$ neutrophils. The CSF protein was $7 \cdot 9 \mathrm{~g} / \mathrm{L}$. The CSF glucose was $0.15 \mathrm{mmol} / \mathrm{L}$ with a plasma glucose of 8.62 mmol/L. Gram and Zeil-Neilsen stains were negative. However on wet mount microscopy numerous amoebae were observed (Figure 1 and Video 1). He had already been commenced on ceftriaxone and dexamethasone to treat presumed bacterial meningitis. In view of the CSF findings and the history of exposure to freshwater a diagnosis of primary amoebic meningoencephalitis (PAM) was considered. Amphotericin B and rifampicin were commenced. Later on the day of admission his condition deteriorated and he required intubation and ventilation. He subsequently went into cardiac arrest and could not be resuscitated. Retrospectively, a polymerase chain reaction (PCR) amplification targeting the 18s RNA gene was performed. ${ }^{1}$ The PCR amplicon was sequenced and 
confirmed to have $100 \%$ homology with the 18s RNA gene of Naegleria fowleri, the cause of PAM.

Naegleria fowleri is a free-living amoeba that typically lives in warm freshwater environments. ${ }^{2}$ Amoebae enter the brain via the olfactory nerve after infected water is inhaled or splashed into the nose. Within the central nervous system Naegleria fowleri amoebae cause an intense inflammatory reaction accompanied by necrosis and haemorrhage. ${ }^{3}$ PAM appears to be increasing in frequency with an expanding geographic footprint. ${ }^{4,5}$ The clinical and CSF findings are difficult to distinguish from bacterial meningitis. ${ }^{5}$ A history of freshwater exposure and symptoms such as the loss of the sense of smell should prompt consideration of the disease. ${ }^{4}$ PAM has an extremely high case fatality rate and there are very few documented survivors. Early diagnosis and prompt initiation of an amphotericin B-based regimen are essential for a good outcome. ${ }^{5}$ Additional drugs have been used such as rifampicin, fluconazole, and azithromycin. ${ }^{4,5}$ To our knowledge this is the first documented case of Naegleria fowleri infection in Vietnam. The case highlights an important, albeit rare, risk of freshwater pearl diving.

\section{Contributors}

NHP, NTHM, HDTN, TTHC, PPL, LHT, TMP, CQT, NVVC and JW were involved with the clinical care of the patient. DNHM, TVTN, SB and JC were involved with the laboratory diagnosis and prepared the images and the video file. All authors contributed to the manuscript.

\section{Conflicts of interests}

The authors confirm that we have no conflicts of interest. 


\section{References}

1. Qvarnstrom $Y$, Visvesvara GS, Sriram R, da Silva AJ. Multiplex real-time PCR assay for simultaneous detection of Acanthamoeba spp., Balamuthia mandrillaris, and Naegleria fowleri. J Clin Microbiol 2006; 44: 3589 - 95

2. Visvesvara GS, Moura H, Schuster FL. Pathogenic and opportunistic freeliving amoebae: Acanthamoeba spp., Balamuthia mandrillaris, Naegleria fowleri, and Sappinia diploidea. FEMS Immunol Med Microbiol 2007; 50: 1 $-26$.

3. Cervantes-Sandoval I, Serrano-Luna J, Garcia-Latorre E, Tsutsumi V, Shibayama M. Characterization of brain inflammation during primary amoebic meningoencephalitis. Parasitol Int/ 2008; 57: 307 e13

4. Kemble SK, Lynfield R, DeVries AS, et al. Fatal Naegleria fowleri infection acquired in Minnesota: possible expanded range of a deadly thermophilic organism. Clin Infect Dis 2012; 54 (6): 805 - 9

5. Heggie TW. Swimming with death: Naegleria fowleri infections in recreational waters. Travel Med Infect Dis 2010; 8 (4): 201 - 6 


\section{Figure legend:}

A: Naegleria fowleri with lymphocytes in CSF (Giemsa stain, x1000); B: Naegleria fowleri in CSF showing cell elongation to aid movement (wet preparation, $\mathrm{x} 1000$ )

Movie legend:

Naegleria fowleri moving in CSF (wet preparation, x1000) 